\title{
BMJ Open Stigma, displacement stressors and psychiatric morbidity among displaced Syrian men who have sex with men (MSM) and transgender women: a cross- sectional study in Lebanon
}

Kirsty Clark (D) , J John Pachankis, ${ }^{1}$ Kaveh Khoshnood, ${ }^{2,3}$ Richard Bränström, ${ }^{4}$ David Seal, ${ }^{5}$ Danielle Khoury, ${ }^{6}$ Fouad M Fouad, ${ }^{6}$ Russell Barbour, ${ }^{7}$ Robert Heimer ${ }^{2,3}$

To cite: Clark K, Pachankis J, Khoshnood K, et al. Stigma, displacement stressors and psychiatric morbidity among displaced Syrian men who have sex with men (MSM) and transgender women: a cross-sectional study in Lebanon. BMJ Open 2021;11:e046996. doi:10.1136/ bmjopen-2020-046996

- Prepublication history and additional supplemental material for this paper are available online. To view these files, please visit the journal online (http://dx.doi.org/10.1136/ bmjopen-2020-046996).

Received 16 November 2020 Revised 12 April 2021 Accepted 15 April 2021
Check for updates

(C) Author(s) (or their employer(s)) 2021. Re-use permitted under CC BY-NC. No commercial re-use. See rights and permissions. Published by BMJ.

For numbered affiliations see end of article.

Correspondence to

Dr Kirsty Clark;

kirsty.clark@yale.edu

\section{ABSTRACT}

Background Displaced Syrians face psychiatric morbidity often resulting from displacement-related stressors (eg, resource scarcity). Both men who have sex with men (MSM) and transgender women among the displaced Syrians are particularly vulnerable to mental health challenges given that they also often face stigma-related stressors (eg, discrimination).

Methods Between January and December 2019 in greater Beirut, 258 Lebanese-born MSM and transgender women and 230 displaced Syrian MSM and transgender women were recruited via respondent-driven sampling to complete an in-person survey assessing displacement-related stressors, stigma-related stressors, depression, anxiety and post-traumatic stress disorder. In the total sample, we first documented the prevalence of psychiatric morbidity among the displaced Syrians; we then assessed associations among displacement-related and stigma-related stressors and each psychiatric outcome.

Results Sixty-three per cent of Syrian participants met criteria for depression compared with $43.8 \%$ of Lebanese participants $(p<0.001) ; 21.3 \%$ of Syrians met criteria for severe anxiety compared with $13.1 \%$ of Lebanese participants $(p<0.05)$ and $33.0 \%$ of Syrians met criteria for post-traumatic stress disorder compared with $18.4 \%$ of Lebanese participants $(p<0.001)$. Among Syrian MSM and transgender women, sociodemographic characteristics, displacement-related stressors and stigma-related stressors were uniquely associated with psychiatric morbidity.

Conclusion Displaced Syrian MSM and transgender women experience higher levels of psychiatric comorbidities than Lebanese MSM and transgender women in part due to compounding exposure to displacement-related stressors and stigma-related stressors. Informed by tenets of minority stress theory and intersectionality theory, we discuss mental health intervention implications and future directions.

\section{INTRODUCTION}

Since March 2011, more than half of Syria's population has been displaced to escape the ongoing armed conflict, with many taking refuge in neighbouring Lebanon. The United

\section{Strengths and limitations of this study}

- This is the first study assessing psychiatric morbidity among Syrian men who have sex with men and transgender women displaced by armed conflict in Lebanon.

- Respondent-driven sampling recruited both Lebanese and displaced Syrians, allowing for comparison of prevalence and determinants of psychiatric morbidity between groups.

- Valid and reliable instruments were used to assess stigma experiences, displacement stressors and psychiatric morbidity.

- The study's cross-sectional design precludes causal inference of determinants of psychiatric morbidity.

- This study assessed discrimination and assault events related to sexual minority status; however, it did not assess discrimination and assaults events related to gender identity or Syrian nationality.

Nations High Commissioner for Refugees (UNHCR) has deemed the Syrian refugee crisis the largest humanitarian emergency in modern history. One and half million fled to Lebanon, which prior to the influx of Syrian refugees had a population of $\leq 4.5$ million and which now hosts the largest proportion of refugees per capita in the world. ${ }^{1}$

Displaced Syrians living in Lebanon face significant psychosocial challenges associated with depression, anxiety and post-traumatic stress disorder (PTSD). Recently, two studies documented that the prevalence of depression and PTSD among samples of displaced Syrians in Lebanon exceeded 27\% and 43\%, respectively. ${ }^{2}{ }^{3}$ Psychiatric morbidity emerges from a confluence of risk factors including pre-existing mental disorders; conflict-related trauma, violence, loss and displacement; and maladjustment to a new environment due to 
poor living conditions, scarcity of resources and intergroup conflict with host communities. ${ }^{45}$

Both men who have sex with men (MSM) and transgender women among the displaced Syrians are particularly vulnerable to the mental health challenges of stigma given their dual minority status both as an MSM or transgender woman and displaced person. ${ }^{6}$ In addition to fleeing their homes to escape war and political instability, Syrian MSM and transgender women also flee to escape identity-related persecution and violence. ${ }^{7}$ Once in Lebanon, however, they often face antigay and antitransgender stigma driven by a conservative legal climate and social attitudes. The Lebanese penal code has been used to criminalise same-sex sexual behaviour through Article 534 which condemns 'sexual intercourse against nature' and gender expression and identity through Article 521 which prohibits men from 'masquerading' as women. In 2018, a district appeals court in Lebanon ruled that consensual sex between people of the same sex is not unlawful; Article 534, however, has not been repealed. MSM and transgender women in Lebanon report negative psychosocial outcomes (eg, concealment and shame) in response to antigay and antitransgender discrimination and harassment. ${ }^{89}$ One recent study found that Syrian MSM in Lebanon experienced more than twice the prevalence of discriminatory or violent events than Lebanese MSM, perhaps owing to the intersection of their MSM status and Syrian nationality. ${ }^{6}$

Minority stress theory posits that discrimination based on sexual or gender identity can lead to internalised stigmatising beliefs and associated psychological distress. ${ }^{10}$ Owing in large part to these experiences, sexual and gender minorities around the world experience elevated rates of psychiatric morbidity compared with their heterosexual, cisgender peers. ${ }^{11} 12$ Yet to our knowledge, only two studies have assessed the prevalence of depression among Lebanese MSM $(26 \%)^{13}$ and transgender women $(66 \%)^{9}$ and neither examined the prevalence or determinants of mental health problems among displaced Syrian MSM and transgender women. The lack of studies including displaced Syrian MSM and transgender women hampers understanding of the relative importance of displacement-related determinants (eg, displacement stressors, resource scarcity and displacement-related discrimination) versus MSM-related and transgenderrelated determinants (eg, experienced and internalised stigma) on psychiatric morbidity in this population. Assessing such determinants can inform tailored mental health interventions deemed critical by UNHCR and other humanitarian organisations for reducing psychiatric morbidity and associated distress among this vulnerable subgroup of Syrians. ${ }^{6}$

Drawing on a large sample of MSM and transgender women recruited by respondent-driven sampling in Lebanon, this study sought to (1) assess and compare the prevalence of common psychiatric disorders (ie, depression, anxiety and PTSD) among Lebanese and Syrian MSM and transgender women and (2) among Syrian MSM and transgender women, examine the relative impact of displacement-specific and MSM and transgenderspecific determinants of psychiatric morbidity. This study represents the first investigation of prevalence and determinants of psychiatric morbidity among displaced Syrian MSM and transgender women.

\section{METHODS}

\section{Participants}

Between January and December 2019, MSM and transgender women in the greater Beirut region were recruited to complete a biobehavioural survey of sociodemographics, mental health, stigma experiences and sexually transmitted infections (STIs) focusing on HIV-risk and protective behaviours. ${ }^{6}$ This article does not report STIrelated results. Eligible participants had been assigned male sex at birth, reported oral or anal sexual intercourse with a male in the past 6 months and provided informed consent. Participants were recruited using respondentdriven sampling ${ }^{14}$ by one of five local non-governmental organisations (NGOs) that offer psychosocial health services, HIV/STI counselling and testing, basic needs (eg, food banks), and legal advocacy for lesbian, gay, bisexual, transgender and queer (LGBTQ) populations. These five NGOs represent the sites providing the most LGBTQ-related services in Lebanon; the NGOs are secular and based in Beirut, but have partnerships across Lebanon including within refugee camps, allowing for geographically diverse recruitment of MSM and transgender women. Briefly, nine Syrian-born seed participants were recruited directly by study personnel. Each then received four coupons to recruit additional participants, and successful recruits were then each given four coupons. Participants received US $\$ 20$ for completing the survey and US\$10 for each subsequently recruited participant. Surveys were conducted in Arabic via in-person interviews with trained study staff at local NGOs or LGBTQ-friendly venues (eg, bars).

MSM and transgender women were included in this study if they completed any mental health assessment (ie, depression, anxiety and post-traumatic stress) and were either Lebanese-born or were Syrian-born and migrated to Lebanon after 15 March 2011 when the Syrian conflict began. For this reason, we can consider all Syrian participants in this study to be displaced Syrians. In total, 594 MSM and transgender women were recruited. We excluded from analyses 19 Syrian-born individuals who migrated to Lebanon before 15 March 2011; 27 participants who were born outside of Lebanon or Syria (eg, Iraq, Jordan, Kuwait); and 60 participants who did not complete any mental health assessments. Our final analytic sample size was 488 .

\section{Patient and public involvement statement}

Stakeholders from local LGBTQ NGOs in greater Beirut, including service providers and MSM and transgender community members, were involved in study development 
including finalising study measures and respondentdriven sampling seed participant recruitment.

\section{Measures}

Sociodemographics

We assessed age, household size, gender identity, education level, monthly income, relationship status and partner gender.

\section{Discrimination and assault}

Stigma-related measures assessed experiences related to sexual minority status; however, experiences specific to gender minority status were not assessed in this study. Discrimination was measured by five yes-or-no questions assessing whether an individual had been refused healthcare, employment, religious services, restaurant or bar service, or housing in the past 12 months because they were believed to be a sexual minority. Assault was measured by three yes-or-no questions assessing whether an individual had experienced verbal harassment, physical abuse or sexual assault in the past 12 months because they were believed to be a sexual minority. These questions have been reliably used to measure discrimination and assault exposure among MSM around the world including in Lebanon. ${ }^{6}$

\section{Internalised stigma}

Two sets of six items measured internalised stigmatising beliefs regarding one's status as a sexual minority or, if applicable, as a Syrian person. Measures were adapted from a validated instrument of internalised HIV-related stigma. $^{15}$

\section{Displacement-related stressors}

Syrian participants reported on two stressors related to displacement. As a measure of unstable housing, Syrian participants reported how many locations they had lived in since moving to Lebanon. As a measure of legal status, Syrian participants reported whether they had an official visa or permit in Lebanon.

\section{Mental health}

Depression was measured by the 20-item self-report Center for Epidemiologic Studies Depression Scale (CES-D) with a cut-off score of $\geq 16$ suggesting the presence of clinically significant depressive symptoms. ${ }^{16}$ Anxiety was assessed by the 21-item self-report Beck Anxiety Inventory (BAI) with a cut-off score of $\geq 26$ suggesting the presence of severe anxiety. ${ }^{17}$ Post-traumatic stress was measured by the 17-item self-report Post-traumatic Stress Disorder CheckList for Civilians (PCL-C) with a cut-off score of $\geq 50$ suggesting probable PTSD. ${ }^{18}$ The CES-D, BAI and PCL-C have been employed as valid instruments assessing depression, anxiety severity and PTSD, respectively, in Arabicspeaking community and displaced populations. ${ }^{19-21}$

\section{Statistical analysis}

Analyses were conducted using SAS V.9.4 and proceeded in three steps. First, descriptive statistics were used to assess sociodemographic, stigma-related stressors and mental health differences between Lebanese-born and Syrian-born MSM and transgender women. Second, simple linear regression models examined unadjusted associations between sociodemographic factors, displacement status (Lebanese-born vs displaced Syrian) and each mental health outcome. Variables that showed significant associations at $\mathrm{p}<0.05$ in bivariate models were retained in adjusted multivariable linear regression models. There were generally very little missing covariate data (see table 1 for all individual variable sample sizes); nonetheless, missing data in regression models were handled via multiple imputation procedures with fully conditional specification, pooling results from five multiply imputed data sets. ${ }^{22}$ Third, we restricted analyses to displaced Syrians and conducted bivariate and multivariable linear regression analyses to assess the unadjusted and adjusted associations, respectively, between sociodemographic characteristics, displacement-related stressors, stigmarelated stressors (ie, discrimination, assault, internalised sexual minority and Syrian stigma) and each mental health outcome. Supplemental logistic regression analyses mirrored the primary analyses but assessed the presence of psychiatric morbidity using binary indicators of mental health cutoffs as outcomes.

\section{RESULTS}

Bivariate analyses showed that displaced Syrians were younger, had less educational attainment and had lower monthly income than Lebanese participants (see table 1). Notably, nearly two-thirds of Syrian participants reported a monthly income of US\$0-US\$500 compared with approximately one-third of Lebanese participants. In total, $86.4 \%$ of the sample identified as a man, and $13.6 \%$ of participants identified as a woman, transgender woman or other gender identity.

Prevalence of psychiatric morbidity in the sample was generally high (see table 2). Sixty-three per cent of Syrians met or exceeded the cut-off for depression compared with $43.8 \%$ of Lebanese participants $(\mathrm{p}<0.001)$. Approximately $21.3 \%$ of Syrians met criteria for severe anxiety compared with $13.1 \%$ of Lebanese participants $(p<0.05)$. Thirty-three per cent of Syrians were considered to have PTSD compared with $18.4 \%$ of Lebanese participants $(\mathrm{p}<0.001)$. Syrian participants reported higher stigmarelated stress including internalised sexual minority stigma and greater exposure to recent discrimination and assault than Lebanese-born participants.

Syrian MSM and transgender women experienced higher levels of depression and post-traumatic stress than Lebanese-born MSM and transgender women in crude and adjusted models (see table 3 ). The association between displacement status and anxiety did not reach significance after adjusting for sociodemographics. In supplemental analyses, Syrians demonstrated a trend of 1.23 greater odds of both depression and PTSD than Lebanese-born participants in adjusted models (see 
Table 1 Sample characteristics among Lebanese and displaced Syrian MSM and transgender women recruited through respondent driven sampling in Lebanon, $\mathrm{N}=488$

\begin{tabular}{|c|c|c|c|c|c|}
\hline \multirow[b]{2}{*}{ Sociodemographic variable } & \multicolumn{2}{|c|}{ Lebanese (n=258; 52.3\%) } & \multicolumn{2}{|c|}{ Displaced Syrian ( $n=230 ; 47.1 \%)$} & \multirow[b]{2}{*}{$\chi^{2}$ or T-value } \\
\hline & $\mathrm{n}$ or mean & $\%$ or SD & $\mathrm{n}$ or mean & $\%$ or SD & \\
\hline Age $(n=486)$ & 28.0 & 7.08 & 26.0 & 4.60 & $3.85^{\star \star \star}$ \\
\hline Household size $(n=482)$ & 3.98 & 2.08 & 3.72 & 2.13 & 1.35 \\
\hline Gender identity $(n=420)$ & & & & & 0.74 \\
\hline Man & 203 & 85.7 & 160 & 87.4 & \\
\hline Woman or transgender woman & 26 & 11.0 & 19 & 10.4 & \\
\hline Other & 8 & 3.4 & 4 & 2.2 & \\
\hline Education level & & & & & $28.87^{\star * *}$ \\
\hline Did not complete primary school & 10 & 3.9 & 11 & 4.8 & \\
\hline Completed primary school & 47 & 18.2 & 70 & 30.4 & \\
\hline Completed secondary school & 46 & 17.8 & 43 & 18.7 & \\
\hline Some college or university & 52 & 20.2 & 63 & 27.4 & \\
\hline Completed university & 103 & 39.9 & 43 & 18.7 & \\
\hline Income (monthly, US\$; n=480) & & & & & $93.48^{\star \star *}$ \\
\hline $0-500$ & 91 & 35.7 & 147 & 65.3 & \\
\hline $501-1000$ & 66 & 25.9 & 72 & 32.0 & \\
\hline $1001-2000$ & 65 & 25.5 & 5 & 2.2 & \\
\hline $2001-4000$ & 32 & 12.6 & 1 & 0.4 & \\
\hline$>4000$ & 1 & 0.4 & 0 & 0.0 & \\
\hline Relationship status ( $n=486$ ) & & & & & 0.91 \\
\hline Single & 168 & 65.4 & 159 & 69.4 & \\
\hline Partnered & 89 & 34.6 & 70 & 30.6 & \\
\hline Gender of partner $(n=159)$ & & & & & 2.61 \\
\hline Cisgender man & 78 & 87.6 & 63 & 90.0 & \\
\hline Cisgender woman & 2 & 2.3 & 1 & 1.4 & \\
\hline Transgender man & 1 & 1.1 & 0 & 0.0 & \\
\hline Transgender woman & 4 & 4.5 & 5 & 7.1 & \\
\hline Other (eg, gender non-conforming) & 4 & 4.5 & 1 & 1.4 & \\
\hline
\end{tabular}

${ }^{*} \mathrm{p}<0.05,{ }^{* *} \mathrm{p}<0.01,{ }^{* * *} \mathrm{p}<0.001$.

MSM, men who have sex with men.

online supplemental table 1). Across models, transgenderidentified participants demonstrated greater psychiatric morbidity than cisgender participants.

Among Syrian MSM and transgender women, sociodemographic characteristics, displacement-related stressors and stigma-related stressors all served as determinants of psychiatric morbidity as assessed by multiple linear regression models (see table 4). Regarding sociodemographic characteristics, lower monthly income and not being in a relationship were significantly associated with higher levels of depression, anxiety and post-traumatic stress. In terms of displacementrelated stressors, the greater number of locations lived since migrating to Lebanon was associated with higher anxiety $(\beta=0.50, \quad \mathrm{p}<0.01)$ and post-traumatic stress $(\beta=0.52, p<0.01)$. Participants who did not have legal status reported higher depression $(\beta=3.63, \mathrm{p}<0.05)$, anxiety $(\beta=4.14, \quad \mathrm{p}<0.05)$ and post-traumatic stress $(\beta=5.81, p<0.01)$ than those with legal status. Exposure to past-year sexual minority discrimination $(\beta=2.16$, $\mathrm{p}<0.05)$ and assault $(\beta=2.23, \mathrm{p}<0.05)$ were each associated with higher depression, while internalised sexual minority stigma was marginally associated $(\beta=0.33$, $\mathrm{p}<0.10)$ and internalised Syrian stigma was not associated with depression. Exposure to sexual minority discrimination $(\beta=2.29, p<0.01)$ and internalised Syrian stigma $(\beta=0.24, p<0.05)$ were associated with more severe anxiety. The only stigma-related stressor significantly associated with post-traumatic stress was sexual minority assault $(\beta=2.31, p<0.05)$. Supplemental logistic regression analyses demonstrated similar, but somewhat 
Table 2 Mental health and stigma differences between Lebanese and displaced Syrian MSM and transgender women, N=488

\begin{tabular}{|c|c|c|c|c|c|}
\hline \multirow[b]{2}{*}{ Mental health or stigma variable } & \multicolumn{2}{|c|}{ Lebanese $(n=258 ; 52.3 \%)$} & \multicolumn{2}{|c|}{ Displaced Syrian $(n=230 ; 47.1 \%)$} & \multirow{2}{*}{$\begin{array}{l}\chi^{2} \text { or } \mathrm{T}- \\
\text { value }\end{array}$} \\
\hline & n or mean & $\%$ or SD & n or mean & $\%$ or SD & \\
\hline Depression† (range: 0-60) & 16.79 & 14.33 & 23.15 & 15.16 & $4.76^{\star \star \star}$ \\
\hline Anxiety $\ddagger$ (range:0-63) & 11.05 & 12.32 & 14.89 & 13.77 & $3.25^{\star \star}$ \\
\hline Severe anxiety cut-off $¥$ (n, \%) & 34 & 13.1 & 49 & 21.3 & $5.68^{*}$ \\
\hline $\begin{array}{l}\text { Post-traumatic stress disorder cut-off }(n=468 \\
n, \%)\end{array}$ & 45 & 18.4 & 74 & 33.0 & $13.11^{\star \star \star}$ \\
\hline Internalised sexual minority stigma (range: 6-30) & 13.27 & 5.14 & 16.50 & 6.37 & $6.12^{\star * *}$ \\
\hline Internalised Syrian stigma (range: 6-30) & - & - & 13.97 & 7.23 & - \\
\hline Sexual minority discrimination (range: $0-5$ ) & 0.50 & 1.04 & 0.77 & 1.13 & $2.73^{\star *}$ \\
\hline
\end{tabular}

${ }^{*} \mathrm{p}<0.05,{ }^{* *} \mathrm{p}<0.01,{ }^{* \star *} \mathrm{p}<0.001$.

†Depression measured by the Center for Epidemiological Studies Depression (CES-D). Clinical depression cut-off denoted by a score of $\geq 16$ on the CES-D.

$\ddagger$ Anxiety assessed by the Beck Anxiety Inventory (BAI). Severe anxiety cut-off denoted by a score of $\geq 26$ on the BAl.

IPost-traumatic stress measured by the PTSD CheckList-Civilian Version (PCL-C). Post-traumatic stress disorder cut-off denoted by a score of $\geq 50$ on the PCL-C.

MSM, men who have sex with men.

attenuated, results to linear regression analyses perhaps due to limited power (see online supplemental table 2).

\section{DISCUSSION}

To our knowledge, this study represents the first study to document the prevalence and determinants of psychiatric morbidity among displaced Syrian MSM and transgender women. Our data, accrued by respondent-driven sampling in 2019, showed substantially elevated prevalence of depression, anxiety and PTSD among displaced Syrian MSM and transgender women compared with Lebanese MSM and transgender women.

Findings from this study are consistent with prior research showing that depression, anxiety and PTSD are elevated among both MSM and transgender women and individuals displaced by armed conflict. ${ }^{2-4} 10-12$ In support of minority stress theory ${ }^{10}$ and intersectionality theory, ${ }^{23}$ displaced Syrian MSM and transgender women in the sample experienced a confluence of stigma-related and displacement-related stressors in response to their interlocking minoritized statuses as both a sexual or gender minority and displaced person. Exposure to such stressors can influence psychiatric morbidity through underlying cognitive processes. ${ }^{24}$ For example, the learned helplessness theory of depression posits that individuals who experience an aversive, uncontrollable event can become helpless due to feeling a lack of control over their circumstances. ${ }^{25}$ Those who attribute the cause of such an aversive, uncontrollable event to internal (ie, due to the person themselves), global (ie, affecting the person's whole life) and stable (ie, unchangeable) factors are most likely to become depressed. ${ }^{25}$ Stigma-related stress events-including discrimination on the basis of minority or displacement status-can be viewed as uncontrollable and global. ${ }^{24}$ When an individual believes themselves the cause of stigma-related stress events, they are more likely to develop depression. Among displaced Syrian MSM and transgender women in this study, sexual minorityrelated discrimination and assault and internalised sexual minority stigma were associated with greater depression while internalised Syrian stigma was not associated with greater depression. Displaced Syrian MSM and transgender women might view their sexual or gender identity status as having an internal cause (ie, being innate) versus their displaced Syrian status as having an external cause (ie, war); MSM-related and transgender-related stigma might therefore be more strongly associated with depression than displacement-related stigma.

Research on the aetiology of anxiety disorders suggests that accounting for contextual influences is critical for understanding how aversive events (eg, stigma-related discrimination and violence) can lead to anxiety or PTSD. ${ }^{26}$ Modern learning theorists suggest that differences in individual factors affect the strength of fear that is conditioned by aversive events. ${ }^{26}$ Such individuallevel differences include previous exposure to traumatic or aversive events, the context of the aversive event (eg, whether the event is controllable or uncontrollable) and postevent experiences (eg, an inflation effect such that the strength of milder fears can be inflated by subsequent traumatic events). On average, almost two-thirds of displaced Syrians in this study reported experiencing at least one form of verbal harassment, physical abuse or sexual assault due to their sexual minority status in the 
Table 3 Linear regression models regressing mental health on sociodemographic characteristics and displacement status among Lebanese and displaced Syrian MSM and transgender women in Lebanon, N=488

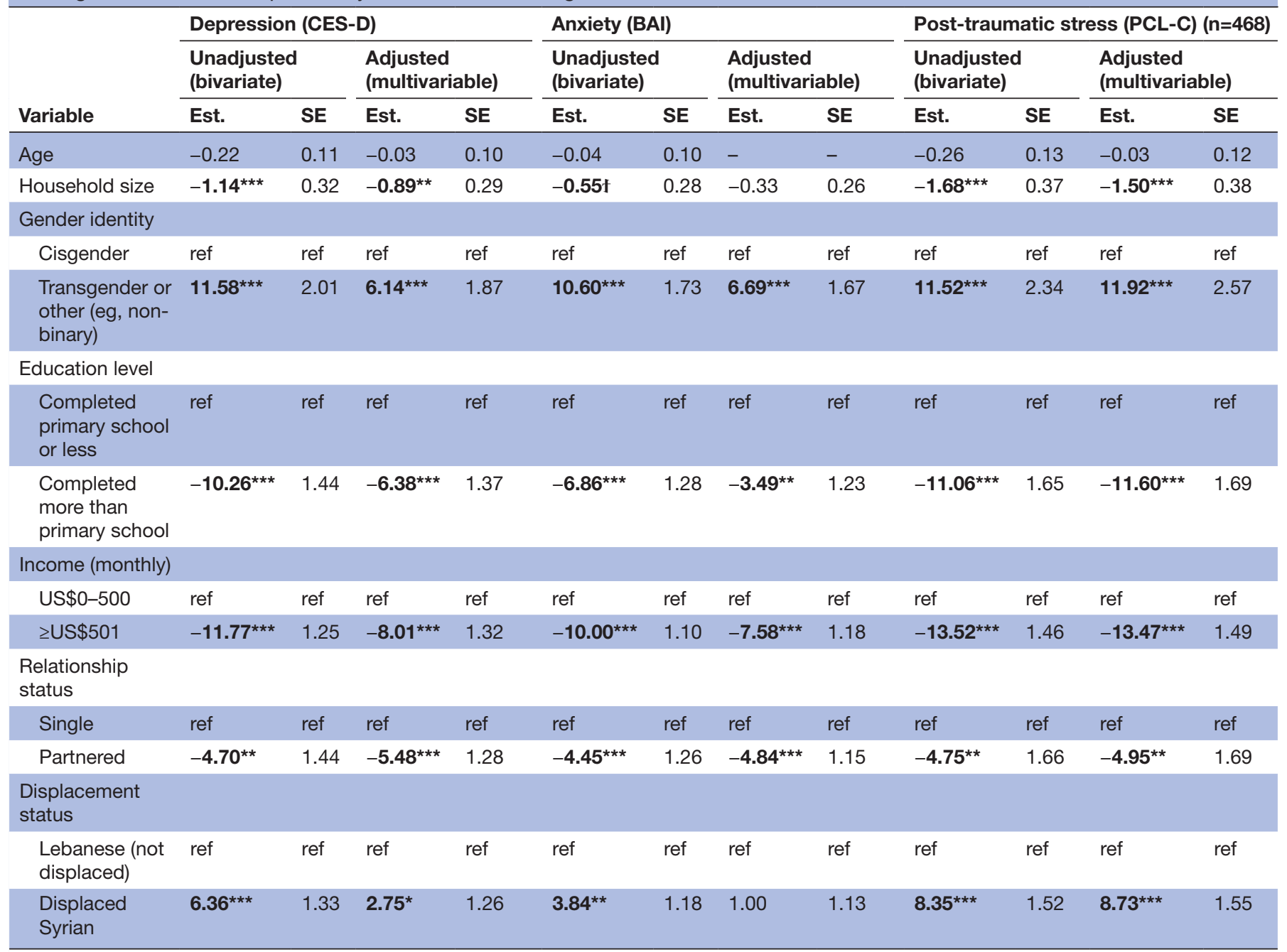

Notation and bold formatting used to denote the following significance: $f \mathrm{p}<0.10,{ }^{*} \mathrm{p}<0.05,{ }^{* *} \mathrm{p}<0.01,{ }^{* \star *} \mathrm{p}<0.001$.

BAI, Beck Anxiety Inventory; CES-D, Center for Epidemiologic Studies Depression Scale; Est., estimate; MSM, men who have sex with men; PCL-C

Post-traumatic Stress Disorder CheckList for Civilians; SE, standard error.

past 12 months. We theorise that such stigma-related stress events are especially likely to lead to anxiety and PTSD due to the perception of stigma-related stressors as pervasive and uncontrollable. Furthermore, the mental health toll of such stigma-related events might be inflated by displaced Syrian MSM and transgender women's likely exposure to previous traumatic or aversive events due to their intersecting statuses. ${ }^{724}$ In support of this theory, displaced Syrian MSM and transgender women demonstrated substantially higher risk of PTSD than Lebanese MSM and transgender women.

The high prevalence of psychiatric comorbidities in this study delineates the need for mental health support for displaced Syrian MSM and transgender women. UNHCR and other humanitarian programmes have emphasised that mental health interventions for vulnerable subgroups of displaced Syrians are critical to reducing psychiatric morbidity and associated distress, yet very few exist. ${ }^{4}$ A recent Cochrane review of mental health promotion, prevention and treatment for displaced people including refugees and asylum seekers found that existing interventions focus primarily on PTSD and trauma-related symptoms rather than anxiety, depression or comorbid mental health problems; few assess cultural appropriateness or acceptability of mental health interventions for displaced populations. ${ }^{27}$ For displaced Syrian MSM and transgender women, mental health interventions should be attuned to the unique intersections of sexual and/or gender minority and displacement status that include coping with stigma and trauma in the face of unchangeable stressors (eg, stigmatising societal attitudes) and uncertainty (eg, regarding legal status). Promising qualitative results were recently published from a pilot study assessing the first mental health/HIV intervention for transgender women in the Middle East. Named Baynetna and conducted in Lebanon, it includes six modules conducted in a weekly, peer-led, groupbased format covering topics including transphobia, 
Table 4 Linear regression models regressing mental health on sociodemographic characteristics, displacement-related stressors and stigma-related stressors among displaced Syrian MSM and transgender women in Lebanon, N=230

\begin{tabular}{|c|c|c|c|c|c|c|c|c|c|c|c|c|}
\hline \multirow[b]{3}{*}{ Variable } & \multicolumn{4}{|c|}{ Depression (CES-D) } & \multicolumn{4}{|c|}{ Anxiety (BAI) } & \multicolumn{4}{|c|}{ Post-traumatic stress (PCL-C) $(n=224)$} \\
\hline & \multicolumn{2}{|c|}{$\begin{array}{l}\text { Unadjusted } \\
\text { (bivariate) }\end{array}$} & \multicolumn{2}{|c|}{$\begin{array}{l}\text { Adjusted } \\
\text { (multivariable) }\end{array}$} & \multicolumn{2}{|c|}{$\begin{array}{l}\text { Unadjusted } \\
\text { (bivariate) }\end{array}$} & \multicolumn{2}{|c|}{$\begin{array}{l}\text { Adjusted } \\
\text { (multivariable) }\end{array}$} & \multicolumn{2}{|c|}{$\begin{array}{l}\text { Unadjusted } \\
\text { (bivariate) }\end{array}$} & \multicolumn{2}{|c|}{$\begin{array}{l}\text { Adjusted } \\
\text { (multivariable) }\end{array}$} \\
\hline & Est. & SE & Est. & SE & Est. & SE & Est. & SE & Est. & SE & Est. & SE \\
\hline \multicolumn{13}{|c|}{ Sociodemographic characteristics } \\
\hline Age & -0.33 & 0.22 & - & - & -0.13 & 0.20 & - & - & $-0.51^{*}$ & 0.24 & 0.12 & 0.22 \\
\hline Household size & -0.17 & 0.47 & - & - & -0.04 & 0.44 & - & - & -0.51 & 0.55 & - & - \\
\hline Cisgender & ref & ref & ref & ref & ref & ref & ref & ref & ref & ref & ref & ref \\
\hline $\begin{array}{l}\text { Transgender or } \\
\text { other (eg, non- } \\
\text { binary) }\end{array}$ & $6.86^{*}$ & 3.23 & 0.70 & 3.21 & $10.25^{\star \star *}$ & 2.69 & 2.89 & 2.67 & $9.01^{*}$ & 3.50 & 1.92 & 3.36 \\
\hline \multicolumn{13}{|l|}{ Education level } \\
\hline \multicolumn{13}{|l|}{ Income (monthly) } \\
\hline US\$0-500 & ref & ref & ref & ref & ref & ref & ref & ref & ref & ref & ref & ref \\
\hline$\geq$ US\$501 & $-7.89^{\star \star *}$ & 2.04 & $-6.02^{\star *}$ & 1.89 & $-7.71^{\star * *}$ & 1.83 & $-5.36^{\star *}$ & 1.74 & $-9.14^{\star \star *}$ & 2.35 & $-7.40^{\star \star *}$ & 2.19 \\
\hline \multicolumn{13}{|l|}{ Relationship status } \\
\hline Single & ref & ref & ref & ref & ref & ref & ref & ref & ref & ref & ref & ref \\
\hline Partnered & $-5.00^{\star}$ & 2.14 & $-3.58 t$ & 1.88 & $-3.29 t$ & 1.97 & $-3.73^{\star}$ & 1.75 & $-6.11^{\star}$ & 2.43 & $-5.42^{*}$ & 2.13 \\
\hline \multicolumn{13}{|c|}{ Displacement-related stressors } \\
\hline Has legal status & $-9.04^{\star \star \star}$ & 1.97 & $-3.63^{\star}$ & 1.87 & $-8.70^{\star \star \star}$ & 1.78 & $-4.14^{\star}$ & 1.71 & $-11.36^{\star \star \star}$ & 2.21 & $-5.81^{\star *}$ & 2.12 \\
\hline \multicolumn{13}{|c|}{ Stigma-related stressors } \\
\hline $\begin{array}{l}\text { Sexual minority } \\
\text { discrimination }\end{array}$ & $5.05^{\star \star \star}$ & 0.82 & $2.16^{*}$ & 0.92 & $5.04^{\star \star \star}$ & 0.73 & $2.29^{\star *}$ & 0.83 & $5.47^{\star \star \star}$ & 0.95 & 1.62 & 1.05 \\
\hline $\begin{array}{l}\text { Sexual minority } \\
\text { assault }\end{array}$ & $5.76^{\star * *}$ & 0.83 & $2.23^{*}$ & 0.94 & $4.40^{* * *}$ & 0.78 & 0.57 & 0.86 & $6.43^{\star * *}$ & 0.94 & $2.31^{*}$ & 1.09 \\
\hline $\begin{array}{l}\text { Internalised sexual } \\
\text { minority stigma }\end{array}$ & $0.51^{\star *}$ & 0.15 & $0.33 t$ & 0.18 & 0.19 & 0.14 & - & - & $0.54^{\star \star}$ & 0.17 & 0.30 & 0.21 \\
\hline $\begin{array}{l}\text { Internalised Syrian } \\
\text { stigma }\end{array}$ & $0.70^{* \star *}$ & 0.13 & 0.20 & 0.16 & $0.49^{\star \star *}$ & 0.12 & $0.24^{*}$ & 0.12 & $0.78^{\star \star *}$ & 0.15 & 0.26 & 0.18 \\
\hline
\end{tabular}

Notation and bold formatting used to denote the following significance: $\mathrm{tp}<0.10,{ }^{*} \mathrm{p}<0.05,{ }^{* *} \mathrm{p}<0.01,{ }^{* * *} \mathrm{p}<0.001$.

BAI, Beck Anxiety Inventory; CES-D, Center for Epidemiologic Studies Depression Scale; Est., estimate; MSM, men who have sex with men; PCL-C,

Post-traumatic Stress Disorder CheckList for Civilians; SE, standard error.

violence, family rejection, self-esteem as well as psychoeducational content related to sexual risk. ${ }^{28}$ In a sample of 16 transgender women (including three displaced individuals), preliminary results showed that Baynetna was feasible, acceptable and promising trends emerged in increasing social support and reducing mental health symptoms. While only a randomised-controlled trial can confirm the efficacy of Baynetna, results from the pilot study suggest that mental health interventions targeting MSM and transgender women in Lebanon might benefit from engaging members through a support group-based format. Recent qualitative evidence from a social support group for LGBTQ refugees in Canada further bolsters the promise of such group-based formats for delivering 
mental health intervention content in a supportive space to normalise stigmatising experiences, share coping skills and material resources (eg, employment opportunities), build social support and community connectedness, and buffer feelings of isolation and loneliness associated with poor mental health. ${ }^{29}$ Mental health interventions for displaced Syrian MSM and transgender women might incorporate tenets of cognitive-behavioural treatment from minority-stress-mental-health treatments that have recently demonstrated efficacy in reducing depression and anxiety symptoms among gender-diverse populations of sexual minorities in the USA ${ }^{30}$ including in a groupbased format with racial/ethnic minority MSM that was adapted based on the framework of intersectionality theory (S Jackson et al, unpublished data, 2020).

While several aspects of this study represent notable strengths, including a large sample recruited by respondent-driven sampling and validated measures assessing psychiatric morbidity, this study is limited in its cross-sectional design that precludes causal inference of determinants of psychiatric morbidity. Studies employing a prospective design are warranted to identify longitudinal predictors and uncover mediators of poorer mental health among displaced Syrian MSM and transgender women. Additionally, the study was designed for MSM, and, while the relatively large proportion of transgender women we recruited represents a relative strength, the study measures did not assess stigma-related stressors specific to gender identity. Future studies should incorporate measures assessing experiences related to identifying as a transgender woman versus MSM. Finally, measures assessing external stigma-related experiences (ie, discrimination and assault) asked about events related to sexual minority status and did not assess discrimination or assault related to Syrian nationality. Assessing the relative impact of discrimination or assault based on MSM and transgender status versus Syrian nationality can further clarify the influence of stigma attribution on psychiatric morbidity in this population.

In support of minority stress theory and aligned with intersectionality theory, displaced Syrian MSM and transgender women experience higher levels of depression, anxiety and PTSD than Lebanese MSM and transgender women in part due to identity-related stigmatisation and displacement-related stressors. Mental health interventions are needed among displaced Syrian MSM and transgender women and might incorporate tenets of cognitive-behavioural science and modern learning theory including stigma-coping content. Such content should focus on building resilience and tackle underlying cognitive processes among those who have faced recurrent, uncontrollable, adverse events (eg, identityrelated assault and rejection, conflict-related trauma and displacement) based on their dual-minority status as an MSM or transgender women and a displaced person. Mental health interventions for displaced Syrian MSM and transgender women delivered in a support group format may be well-poised to offer a supportive, community-based environment while also representing a cost-effective modality.

Author affiliations

${ }^{1}$ Social and Behavioral Sciences, Yale University School of Public Health, New

Haven, Connecticut, USA

${ }^{2}$ Epidemiology of Microbial Diseases, Yale University School of Public Health, New Haven, Connecticut, USA

${ }^{3}$ Center for Interdisciplinary Research on AIDS, Yale University, New Haven, Connecticut, USA

${ }^{4}$ Clinical Neuroscience, Karolinska Institutet, Stockholm, Sweden

${ }^{5}$ Global Community Health and Behavioral Sciences, Tulane University School of Public Health and Tropical Medicine, New Orleans, Louisiana, USA

${ }^{6}$ American University of Beirut, Beirut, Lebanon

${ }^{7}$ Biostatistics, Yale University School of Public Health, New Haven, Connecticut, USA

Twitter Kirsty Clark @kirstyclarkphd

Contributors KAC, JP, RBr and RH: conceptualised the manuscript. KK, FMF, DS and RH: supervised the study. DK: collected data. KAC and RBa: conducted the analyses. KAC: prepared the first draft of the article and revised it based on the feedback from JP, RBr, KK, DK, DS and RH. All authors reviewed and approved the article.

Funding This project was funded by the National Institute of Child and Human Development (R21HD089820).

Competing interests None declared.

Patient consent for publication Not required.

Ethics approval This study was approved by the Yale Human Subjects Committee and the Institutional Review Board at the American University of Beirut.

Provenance and peer review Not commissioned; externally peer reviewed.

Data availability statement Data are available upon reasonable request. Data are available by emailing Robert Heimer at Robert.Heimer@yale.edu or corresponding at Robert Heimer, Yale School of Public Health, 60 College St., PO Box 208034, New Haven, CT 06520-8034, USA.

Supplemental material This content has been supplied by the author(s). It has not been vetted by BMJ Publishing Group Limited (BMJ) and may not have been peer-reviewed. Any opinions or recommendations discussed are solely those of the author(s) and are not endorsed by BMJ. BMJ disclaims all liability and responsibility arising from any reliance placed on the content. Where the content includes any translated material, BMJ does not warrant the accuracy and reliability of the translations (including but not limited to local regulations, clinical guidelines, terminology, drug names and drug dosages), and is not responsible for any error and/or omissions arising from translation and adaptation or otherwise.

Open access This is an open access article distributed in accordance with the Creative Commons Attribution Non Commercial (CC BY-NC 4.0) license, which permits others to distribute, remix, adapt, build upon this work non-commercially, and license their derivative works on different terms, provided the original work is properly cited, appropriate credit is given, any changes made indicated, and the use is non-commercial. See: http://creativecommons.org/licenses/by-nc/4.0/.

ORCID iD

Kirsty Clark http://orcid.org/0000-0002-9626-8460

\section{REFERENCES}

1 UNHCR the UN refugee agency. Lebanon: Fact sheet, 2020. Available: https://reporting.unhcr.org/sites/default/files/UNHCR\% 20Lebanon\%20Fact\%20Sheet\%20-\%20January\%202020.pdf

2 Kazour F, Zahreddine NR, Maragel MG, et al. Post-traumatic stress disorder in a sample of Syrian refugees in Lebanon. Compr Psychiatry 2017;72:41-7.

3 Naja WJ, Aoun MP, El Khoury EL, et al. Prevalence of depression in Syrian refugees and the influence of religiosity. Compr Psychiatry 2016;68:78-85.

4 Abou-Saleh MT, Hughes P. Mental health of Syrian refugees: looking backwards and forwards. Lancet Psychiatry 2015;2:870-1.

5 Yassin N, Osseiran T, Rassi R. No place to stay? Reflections on the Syrian refugee shelter policy in Lebanon. Beirut, Lebanon: United 
Nations Human Settlements Programme and the American University of Beirut, 2015

6 Orr L, Shebl FM, Heimer R, et al. Violence and discrimination against men who have sex with men in Lebanon: the role of international displacement and migration. J Interpers Violence 2019:088626051988468.

7 Alessi EJ, Kahn S, Woolner L, et al. Traumatic stress among sexual and gender minority refugees from the middle East, North Africa, and Asia who fled to the European Union. J Trauma Stress 2018;31:805-15

8 Wagner GJ, Aunon FM, Kaplan RL, et al. Sexual stigma, psychological well-being and social engagement among men who have sex with men in Beirut, Lebanon. Cult Health Sex 2013;15:570-82.

9 Kaplan RL, Nehme S, Aunon F, et al. Suicide risk factors among trans feminine individuals in Lebanon. Int $J$ Transgend 2016;17:23-30.

10 Meyer IH. Prejudice, social stress, and mental health in lesbian, gay, and bisexual populations: conceptual issues and research evidence. Psychol Bull 2003;129:674-97.

11 Batchelder AW, Safren S, Mitchell AD, et al. Mental health in 2020 for men who have sex with men in the United States. Sex Health 2017;14:59-71.

12 Reisner SL, Poteat T, Keatley J, et al. Global health burden and needs of transgender populations: a review. Lancet 2016;388:412-36.

13 Wagner GJ, Ghosh-Dastidar B, El Khoury C, et al. Major depression among young men who have sex with men in Beirut, and its association with structural and sexual minority-related stressors, and social support. Sex Res Social Policy 2019;16:513-20.

14 Heckathorn DD. Respondent-driven sampling: a new approach to the study of hidden populations. Soc Probl 1997;44:174-99.

15 Kalichman SC, Simbayi LC, Cloete A, et al. Measuring AIDS stigmas in people living with HIV/AIDS: the internalized AIDS-related stigma scale. AIDS Care 2009;21:87-93.

16 Radloff LS. The CES-D scale: a self-report depression scale for research in the general population. Appl Psychol Meas 1977;1:385-401.

17 Ulusoy M, Sahin NH, Erkmen $\mathrm{H}$. The Beck anxiety inventory: psychometric properties. J Cogn Psychother 1998;12:163-72.

18 Ruggiero KJ, Del Ben K, Scotti JR, et al. Psychometric properties of the PTSD checklist-Civilian version. J Trauma Stress 2003;16:495-502.
19 Thapa SB, Hauff E. Psychological distress among displaced persons during an armed conflict in Nepal. Soc Psychiatry Psychiatr Epidemiol 2005;40:672-9.

20 Kazarian SS, Taher D. Validation of the Arabic center for epidemiological studies depression (CES-D) scale in a Lebanese community sample. Europ J Psychol Assess 2010;26:68-73.

21 Kira IA, Ramaswamy V, Lewandowski L, et al. Psychometric assessment of the Arabic version of the internalized stigma of menta illness (ISMI) measure in a refugee population. Transcult Psychiatry 2015;52:636-58.

22 Janssen KJM, Donders ART, Harrell FE, et al. Missing covariate data in medical research: to impute is better than to ignore. $J$ Clin Epidemiol 2010;63:721-7.

23 Crenshaw K. Mapping the margins: intersectionality, identity politics, and violence against women of color. Stanford Law Rev 1991;43:1241.

24 Hatzenbuehler ML. How does sexual minority stigma "get under the skin"? A psychological mediation framework. Psychol Bull 2009;135:707-30.

25 Abramson LY, Seligman ME, Teasdale JD. Learned helplessness in humans: critique and reformulation. J Abnorm Psychol 1978;87:49-74.

26 Mineka S, Zinbarg R. A contemporary learning theory perspective on the etiology of anxiety disorders: it's not what you thought it was. Am Psychol 2006;61:10-26.

27 Uphoff E, Robertson L, Cabieses B, et al. An overview of systematic reviews on mental health promotion, prevention, and treatment of common mental disorders for refugees, asylum seekers, and internally displaced persons. Cochrane Database Syst Rev 2020;9:CD013458.

28 Kaplan RL, El Khoury C, Wehbe S, et al. Pilot results from the first HIV/AIDS intervention among transgender women in the middle East: gender affirmation and social support from within trans communities in Beirut, Lebanon. AIDS Res Hum Retroviruses 2020;36:501-12.

29 Logie CH, Lacombe-Duncan A, Lee-Foon N, et al. "It's for us newcomers, LGBTQ persons, and HIV-positive persons. You feel free to be": a qualitative study exploring social support group participation among African and Caribbean lesbian, gay, bisexual and transgender newcomers and refugees in Toronto, Canada. BMC Int Health Hum Rights 2016;16:1-10.

30 Pachankis JE, McConocha EM, Clark KA, et al. A transdiagnostic minority stress intervention for gender diverse sexual minority women's depression, anxiety, and unhealthy alcohol use: a randomized controlled trial. J Consult Clin Psychol 2020;88:613-30. 